\title{
1st International Workshop on: 'Designing for Participatory Learning' Building from Open Source Success to Develop Free Ways to Share and Learn
}

\author{
Andreas Meiszner ${ }^{1}$, Ioannis Stamelos ${ }^{2}$, and Sulayman K. Sowe ${ }^{3}$ \\ ${ }^{1}$ Institute of Educational Technology, The Open University, \\ Milton Keynes, MK7 6AA, UK \\ ${ }^{2}$ Department of Informatics, Aristotle University, \\ 54124 Thessaloniki, Greece \\ ${ }^{3}$ UNU-Merit, Keizer Karelplein 19, \\ 6211 TC Maastricht, The Netherlands
}

\begin{abstract}
The Open Source world shows how volunteer collaboration can lead to great products and to great learning. We want to further explore at this workshop what happens using approaches from that community to break barriers between teachers and learners for today's Internet-savvy young people to design and co-construct sites for participatory learning. The aim of this workshop is to explore the barriers for this type of learning in higher education settings. Content creation, knowledge exchange, community dynamics, and the impact on the boundary between formal and informal education are key subjects of this workshop.
\end{abstract}

\section{Introduction}

There is an ever growing body of research conducted about FLOSS that has built a solid starting base to examine how some of the underlying FLOSS principles might be transferred to higher education. Such research is looking at FLOSS from many different perspectives. Research in FLOSS from an educational perspective (Glott et al. 2007, Weller \& Meiszner 2008, Meiszner et al. 2008, Stamelos 2008) indicates that the success of FLOSS as a learning ecosystem is less related to state of the art technology used within such communities, but rather relates to organizational aspects.

FLOSS communities increasingly influence teaching and learning, and content quality and delivery at a rate unprecedented in the history of both software development and education (Glott et al. 2007). FLOSS communities are a good example for open participatory learning ecosystems (Brown \& Adler 2008) in which individuals interact and collaborate with their peers to solve problems or to exchange ideas. From the 'FLOSS perspective' it becomes obvious that traditional educational approaches, but even the Open Educational Resource movement fall short in some points related to the opportunities the participatory web provides, in particular related to content, support and underlying tools (Meiszner et al. 2008c). Most strikingly, the traditional way of resource creation using the traditional role distribution models that 
clearly distinguishes between educators as creators and learners as consumer is still predominant.

Given the number of research available on FLOSS and the growing landscape of initiatives aimed at opening up education and experimenting with novel approaches this workshop therefore aims at addressing a number of aspects, such as:

1. How can traditional education better master the challenges of new learning opportunities provided by the Internet and its communities?

2. How to systematically combine formal and informal learning within an unfettered informal learning environment?

3. Which are suitable approaches to course sourcing that are open in the sense of interaction between students from various institutions and individuals outside of formal education?

4. How can principles of decentralised and self-organised learning be applied to Open Educational Resources to create comprehensive, sustainable open and participatory learning ecosystems?

5. Which are the challenges and opportunities once blurring the boundaries between formal and informal education?

6. How could formal education monitor properly the learning processes and outcomes within such learning environments?

7. What might be new higher education revenue models associated to such models?

8. Computer Science Education \& Open Source projects are an obvious candidate for such type of learning, how to maximise mutual benefits and which are the possible application models?

\section{References}

Brown, J.S., Adler, R.P.: Minds on Fire: Open Education, the Long Tail, and Learning 2.0. EDUCAUSE Review 43(1), 16-32 (2008)

Glott, et al.: FLOSSCom Phase 1 Report: Analysis of the Informal Learning Environment of FLOSS Communities, FLOSSCom Project (2007)

Meiszner, A., Glott, R., Sowe, S.K.: Preparing the Ne(x)t Generation: Lessons learnt from Free / Libre Open Source Software. GUNI - Global University Network for Innovation (September 9, 2008c)

Meiszner, et al.: Free / Libre Open Source Software (FLOSS-like) education transfer report, FLOSSCom Project (2008)

Stamelos, I.: Teaching Software Engineering with Free/Libre Open Source Projects. International Journal of Open Source Software \& Process (IJOSSP) 1(1), 72-90 (2008)

Weller, M., Meiszner, A.: FLOSSCom Phase 2: Report on the effectiveness of a FLOSS-like learning community in formal educational settings, FLOSSCom Project (2008) 